Personality and Mental Health

8: 306-319 (2014)

Published online 2 September 2014in Wiley Online Library

(wileyonlinelibrary.com) DOI 10.1002/pmh.1268

\title{
Transmission of parental neuroticism to offspring's depression: The mediating role of rumination
}

NATALIE SACHS-ERICSSON ${ }^{1}$, EDWARD A. SELBY ${ }^{2}$, JENNIFER L. HAMES ${ }^{1}$, THOMAS E. JOINER ${ }^{1}$, KAREN L. FINGERMAN ${ }^{3}$, STEVEN H. ZARIT $^{4}$, KIRA S. BIRDITT ${ }^{5}$ AND LORI M. HILT ${ }^{6},{ }^{1}$ Department of Psychology, Florida State University; ${ }^{2}$ Department of Psychology, Rutgers University; ${ }^{3}$ Department of Human Development and Family Sciences, University of Texas at Austin; ${ }^{4}$ Department of Human Development and Family Studies, Pennsylvania State University; ${ }^{5}$ Institute for Social Research, University of Michigan; ${ }^{6}$ Department of Psychology, Lawrence University

\section{ABSTRACT}

Rumination is a cognitive process that involves repetitively focusing on the causes, situational factors and consequences of one's negative emotion, and it is a potent risk factor for depression. Parental depression and neuroticism may exert an influence on offspring's development of rumination, which may increase offspring's risk for depression. The current study included 375 biological parent-offspring dyads. Parents were assessed for depressive symptoms and neuroticism; adult offspring were assessed for depressive symptoms and rumination. Structural equation modelling was used to examine the effects of parental depressive symptoms and parental neuroticism on adult offspring's depression, and to determine whether offspring's rumination mediated this relationship. Results provided evidence that offspring's rumination fully mediated the relationship between parental neuroticism and offspring's depressive symptoms. Parental depressive symptoms and neuroticism may contribute a genetic predisposition for depressive symptoms in offspring, but it also may promote an environment in which maladaptive cognitive processes, such as rumination, are learned. Given the role that rumination plays in mediating the association between neuroticism and depressive symptoms-targeting rumination in the treatment of high risk individuals would be important in reducing onset of depressive disorders. Copyright (C) 2014 John Wiley $\mathcal{G}$ Sons, Ltd.

Parental depression has been shown to be a genetic risk factor for depression in offspring (Cohen-Woods, Craig, \& McGuffin, 2013; Monroe \& Reid, 2008; Plomin et al., 2001; Rice, Harold, \& Thapar, 2002). Additionally, there is evidence that parental neuroticism contributes to the genetic transmission of depressive symptoms from parents to offspring (Kendler, Neale, Kessler,
Heath, \& Eaves, 1993). However, the offspring's individual characteristics may mediate the relationship between parental factors and the offspring's risk for depression. One of the most potent of these factors may be maladaptive thinking patterns, particularly rumination (Susan NolenHoeksema, Wisco, \& Lyubomirsky, 2008). The current study had two goals: first, to examine the 
effects of parental depressive symptoms and neuroticism on the offspring's depressive symptoms; and second, to determine if offspring's level of rumination mediated this relationship.

Rumination (Nolen-Hoeksema, 1991) is a cognitive process that involves repetitive thinking about the causes, situational factors, and consequences of a negative emotional experience. In other words, rumination can be thought of as continuously thinking about and attending to emotionally negative stimuli, in a passive manner, without active problem-solving. Rumination has consistently been found to be a robust and potent predictor of both the onset and maintenance of depression (Hankin, 2008; Nolen-Hoeksema, 2000; Susan Nolen-Hoeksema et al., 2008). Recent twin research suggests that while the heritable influences on rumination are small, they account for the much of the relationship between rumination and depression (Moore et al., 2013).

The response styles theory (Nolen-Hoeksema, 1991) was proposed to explain the insidious relationship between rumination and negative affect. Although rumination is related to other negative cognitive styles (e.g. attribution theory (Abramson, Seligman, \& Teasdale, 1978), negative automatic thoughts, self-focused attention or private selfconsciousness and worry (Papageorgiou \& Wells, 2008), Nolen-Hoeksema and colleagues (2008) contend that rumination has a unique relationship to depression. In fact, rumination continues to be related to depression even after controlling for neuroticism and other negative cognitive styles (Papageorgiou \& Wells, 2008; Spasojević \& Alloy, 2001).

There is evidence that depression is a heritable disorder, as genetics have been found to contribute to the transmission of parental depression to offspring in large twin studies (e.g. Kendler et al., 1986) and in a meta-analysis of studies examining genetic and environmental influences on depression (Sullivan, Neale, \& Kendler, 2000). However, these studies also concluded that environmental influences (e.g. the effect of parental pathology on the family climate) were also etiologically significant. Thus, both genes and the environment appear to influence offspring's risk for depression.

Parental neuroticism may also confer vulnerability to depressive symptoms in offspring (Kendler et al., 1993). Neuroticism is one of the dimensions of the five-factor personality model, characterized by a chronic level of emotional instability and proneness to psychological distress (APA, 2006). Neuroticism is a stable personality trait characterized by frequent negative emotional states (e.g. sadness, anger, guilt, anxiety and shame)(Eysenck \& Eysenck, 1975; Hirschfeld et al., 1983; McCrae \& Costa Jr, 1997). Both cross-sectional (Krueger, 1999) and prospective (e.g. Kendler, Gatz, Gardner, \& Pedersen, 2006) studies have found neuroticism to be strongly associated with risk for major depression. Neuroticism also appears to be highly heritable (Clark, Watson, \& Mineka, 1994; Plomin et al., 2001), indeed heritability estimates are around $50 \%$. There also appears to be a genetic association between neuroticism and depression, as Kendler and colleagues (1993) concluded that approximately $55 \%$ of the genetic liability of major depression appeared to be shared with neuroticism. Thus, parental neuroticism may be genetically transmitted to offspring, increasing their risk for depression.

Neuroticism may also increase risk for rumination (Hervas \& Vazquez, 2011; Nolan, Roberts, $\&$ Gotlib, 1998). Whereas previous studies have not directly examined the association between parental neuroticism and offspring rumination, studies have examined association between neuroticism and rumination within the individual. Specifically, adolescents with high negative affect were more likely to ruminate about stressful events, which then predicted increases in depressive symptoms (Mezulis, \& Rudolph, M., 2012). Additionally, in a study of adults, cross-lagged analyses revealed that whereas ruminative selffocus predicted negative affect at a subsequent occasion, negative affect also predicted ruminative self-focus at a subsequent occasion (Moberly \& Watkins, 2008). 
Available research strongly suggests a mediational model in which neuroticism leads to rumination, which in turn is related to depression (Muris, Roelofs, Rassin, Franken, \& Mayer, 2005). Research supports a mediational model in clinical and non-clinical samples (Lo, Ho, \& Hollon, 2008; Roelofs, Huibers, Peeters, \& Arntz, 2008; Roelofs, Huibers, Peeters, Arntz, \& van Os, 2008; Spasojević \& Alloy, 2001; Verstraeten, Vasey, Raes, \& Bijttebier, 2009). For example, in a study of undergraduates, a mediational model was found in which neuroticism was associated with the cognitive factors of worry and rumination, which in turn were related to anxiety and depression (Muris et al., 2005). In adolescents (aged 14-18), the relationship between neuroticism and depression was found to be mediated by rumination (Mezulis, Priess, \& Hyde, 2011). In undergraduates rumination partially mediated the relation between neuroticism and depression (Roelofs et al., 2008). In a sample followed longitudinally from birth to adolescence, rumination significantly mediated the association between infancy negative emotionality and age 15 depressive symptoms (Mezulis et al., 2011).

Parental depression and neuroticism may also contribute to a negative family environment (i.e. negative affect, irritability, criticism, guilt, etc.) that increases offspring's risk for developing maladaptive coping styles such as rumination (Natsuaki et al., 2014). For example, Rice and colleagues (2006) provided evidence for a significant gene-environment interaction whereby genetically vulnerable children and adolescents were at increased risk of developing depressive symptoms if they were also exposed to family conflict.

In developing a theoretical model for understanding the transmission of parental depression to offspring, Goodman and Gotlib (1999) commented that depressed parents often express negative cognitions and model maladaptive behaviours and poor coping behaviours. Thus, they proposed that one mechanism of transmission is through offspring learning and copying of the parent's depressogenic cognitive styles and behaviours. In fact, longitudinal research found that the development of rumination in adolescents was associated with parental expression of emotions such as guilt and sadness (Hilt, Armstrong, \& Essex, 2011). Thus, depressed parent's expression of negative affect (i.e. neuroticism) and negative cognitions during times of stress may deprive children of the opportunity to learn effective coping styles.

\section{The present study}

In the present study, we examined the hypothesis that parental depressive symptoms and neuroticism would influence the development of rumination and depression in their adult offspring. Specifically, we hypothesized that:

(1) Parental depressive symptoms and neuroticism would lead to rumination in offspring,

(2) Offspring's rumination would predict offspring's depressive symptoms, and

(3) Offspring's rumination would mediate the relationship between parental depression and parental neuroticism on offspring's depression.

\section{Method}

\section{Participants}

Data were drawn from The Family Exchanges Study (Fingerman, Miller, Birditt, \& Zarit, 2009) examining middle-aged parents and their grown children. The larger study included families in which multiple children (i.e. biological, adopted and stepchildren) in the same family participated in interviews (591 parent-offspring dyads); however, the sample for the present study consisted of middle-aged parents (age 40-60) and one of their biological offspring over the age of 18 . Using these criteria, there were a total of 375 parentoffspring dyads $(N=750)$.

Participants resided in the Philadelphia Primary Metropolitan Statistical Area (PMSA), encompassing five counties in southeastern 
Pennsylvania and four counties in New Jersey including urban, suburban and rural areas (Pennsylvania State Data Center, 2001). For the middle-aged parents, a stratified sampling procedure was used to obtain distributions by age (aged 40-50 and 51-60) and gender. Potential participants were identified via lists from Genesys Corporation and random digit dialling within regional area codes. Genesys Corporation derived lists from the white pages, automobile registration, driver's licenses, voter registrations, birth records, consumer surveys and coupon redemption information. Participants provided the name, age and gender of up to three living adult offspring. Most participants (88\%) had three or fewer children over age 18 . The offspring participated through phone interviews or a web-based survey.

In the current study, to avoid biassing, the results by including more than one child from each family, among parents for whom we interviewed more than one of their children, a random numbers programme was used to choose only one child. Because of the potential for genetic transmission, we included only biological children, thus resulting in the 375 dyads $(29.3 \%$ motherdaughter pairs, $24.8 \%$ father-son pairs, $22.4 \%$ father-daughter pairs and 23\% mother-son pairs). Table 1 describes the demographics of the middleaged parents and their offspring included in the current study. Among the parents, the average age was 51.01 years $(\mathrm{SD}=4.8)$. Offspring's average age was $23.51(\mathrm{SD}=5.02)$. It should be noted that the incomes of the parents were relatively high-which may represent a response bias.

The current study was approved by the human subjects committees at Purdue University and the Florida State University. Consent was obtained from participants.

Structural equation modelling in relation to measures

Because we used structural equation modelling (SEM), items obtained from scales were used to generate latent variables in the analyses, rather than simple composite measures. Thus, scale
Table 1: Parent's and offspring's demographics

\begin{tabular}{|c|c|c|}
\hline & $\begin{array}{l}\text { Parents mean } \\
\text { and SD }\end{array}$ & $\begin{array}{l}\text { Offspring mean } \\
\text { and SD }\end{array}$ \\
\hline Age & $51.1(4.8)$ & $23.51(5.02)$ \\
\hline Neuroticism & $2.6(0.7)$ & - \\
\hline Depression & $1.4(0.6)$ & $1.7(0.74)$ \\
\hline \multicolumn{3}{|l|}{ Sex } \\
\hline Female & $47.2 \%$ & $51.7 \%$ \\
\hline \multicolumn{3}{|l|}{ Income } \\
\hline$<\$ 10000$ & $3.8 \%$ & $16.1 \%$ \\
\hline$\$ 10001-\$ 25000$ & $4.6 \%$ & $9.1 \%$ \\
\hline$\$ 25001-\$ 40000$ & $6.0 \%$ & $15.2 \%$ \\
\hline$\$ 40001-\$ 75000$ & $30.0 \%$ & $22.2 \%$ \\
\hline$\$ 75001-\$ 100000$ & $19.6 \%$ & $17.5 \%$ \\
\hline$>\$ 100000$ & $36.0 \%$ & $19.9 \%$ \\
\hline \multicolumn{3}{|l|}{ Ethnicity } \\
\hline Caucasian & $71.0 \%$ & $70.3 \%$ \\
\hline African-American & $23.3 \%$ & $20.9 \%$ \\
\hline Asian & $0.3 \%$ & $0.3 \%$ \\
\hline White/Hispanic & $0.3 \%$ & $1.1 \%$ \\
\hline White/African & $1.6 \%$ & \\
\hline American & & $1.9 \%$ \\
\hline Other & $3.5 \%$ & $5.5 \%$ \\
\hline \multicolumn{3}{|l|}{ Education } \\
\hline Some high school & $1.3 \%$ & $7.2 \%$ \\
\hline High school graduate & $28.1 \%$ & $21.3 \%$ \\
\hline Some college & $30.1 \%$ & $44.5 \%$ \\
\hline College graduate & $23.7 \%$ & $21.1 \%$ \\
\hline Post graduate & $16.8 \%$ & $5.9 \%$ \\
\hline
\end{tabular}

scores were not used in the primary analyses. This was carried out in order to include the individual weight of each criterion to contribute to the overall latent construct, rather than to simply use a sum of all criteria. This allows for the ability to refine each latent variable and remove any poorly fitting items. Latent variables also have the advantage of capturing the common underlying variance among the items in a way that results in reduced standard error compared with a composite measure. SEM also can take measurement error into account and thus provide more reliable information about the relationships between variables. Finally, some have argued that SEM may offer a more complex understanding of the relationship among constructs (Muthén \& Muthén, 2007). 


\section{Assessment measures}

Interviews. Parents and their offspring were interviewed separately via phone or web-based surveys. Much of the material in the parent and offspring surveys was the same, but there were also some differences in questions. For example, the parent sample had no measure of rumination, which was included in the offspring survey. Parents completed computer-assisted telephone interviews that lasted approximately one hour. Parents provided the name, age and gender of each living child and each living parent. Several measures not included in the current study were also obtained from the parents. For example, for each child over the age of 18, each parent provided information regarding financial and emotional support (e.g. socializing, advice, finances and talking about daily events), problems with children in the past 2 years, quality of relationship scales and so forth. Additionally, parents were assessed for functional disability and traumatic life events.

In the full data set, offspring answered the survey either via landline (46\%), cell phone (40\%) or a web-based survey (14\%). Previous research has shown that there is little difference in responses when completing a survey by phone response or by using a paper survey (Groves \& Mathiowetz, 1984).

Demographics. The interview included a comprehensive demographic section. We included offspring's income in the model, as low income has been consistently shown to be related to depression (Plant \& Sachs-Ericsson, 2004). Low income may be stressful and lead to more depression, which has been well documented (Belle Doucet, 2003). However, individuals who are depressed, or have other mental health problem, also tend to function less well, which then leads to lower incomes (Blane, Smith, \& Bartley, 1993).

Brief symptom inventory. Both parents and offspring completed the Brief Symptom Inventory subscale for depression, which is a five-item scale with good reliability and validity (Derogatis, 2000; Derogatis \& Melisarator, 1983).

Participants rated how often they felt the following symptoms over the past 7 days on a scale of 1 (not at all) to 5 (quite a bit): loneliness, feeling blue, loss of interest, hopelessness and worthlessness. Cronbach's alphas were adequate (parent depression $=0.79$; offspring depression $=0.83$ ) .

The brief symptom inventory (BSI) was developed from its longer parent instrument, the symptom checklist (SCL-90-R)(Derogatis, 2000). As reported by Derogatis (2000), the test-retest of the BSI and internal consistency of the BSI have been shown to be very good, and its correlations with the comparable dimensions of the SCL-90-R are quite high. Several criterion-oriented validity studies have also been completed with this instrument (Derogatis \& Melisarator, 1983)(Derogatis \& Savitz, 2000). Specifically, high convergence between BSI scales and like dimensions of the Minnesota Multiphasic Personality Inventory (MMPI) provide good evidence of convergent validity, and factor analytic studies of the internal structure of the scale contribute evidence of construct validity.

Nonetheless, the assessment of depressive symptoms was for only 1-week duration. There was no assessment of lifetime depressive symptom severity. This is an important limitation of the study.

\section{Parental neuroticism}

Parents rated how well each item described themselves using the following scale: $(1=a$ lot, 2 =some, $3=$ a little and $4=$ not at all). Four items assessed neuroticism (i.e. moody, worrying, nervous and calm). However, the item 'Calm' did not significantly load on the latent construct neuroticism in the SEM model; thus, it was removed from the model for better fit. The scale's alpha with the removal of calm was 0.67.

The neuroticism scale items were obtained from the five-factor personality dimensions and adapted from the Midlife Development in the United States (MIDUS) conducted by the MacArthur Foundation research network on 
successful midlife (Lachman \& Weaver, 1997). The measure of neuroticism consisting of the four items culled mainly from Goldberg's (Goldberg, 1992) big-five markers. The neuroticism scale derived from the MIDUS has been widely used. It has been reported to have good validity (Turiano, Mroczek, Moynihan, \& Chapman, 2013) and validated against longer measures of neuroticism such as the NEO-PI scale of neuroticism, also known to have high stability (Staudinger, Fleeson, \& Baltes, 1999).

This four-item neuroticism scale has been used in a number of published reports that have documented its construct validity. Specifically, in these studies, it was negatively correlated with subjective physical health and global well-being (Staudinger et al., 1999), as well as social support, future-oriented life planning, perceived control and life satisfaction (Prenda \& Lachman, 2001). It was positively correlated with 1 -month negative affect and global reports of physical health (Mroczek \& Kolarz, 1998), as well as stressful life events over the course a year (Prenda \& Lachman, 2001). These previous studies document the construct validity of this four-item measure.

Offspring rumination. The offspring interview included a scale that assessed Beliefs and Attitudes, which included the following items related to rumination: (1) When something in my life doesn't turn out the way I hoped I think and talk about it over and over; (2) When something in my life doesn't turn out the way I hoped, I find it hard to move on to the next thing; and (3) I keep thinking things will not go my way. Participants rated each item from 1 (strongly agree) to 4 (strongly disagree). Cronbach's alpha was 0.70.

The rumination items were taken from the sixitem Cognitive Interference scale for the MIDUS. Cognitive Interference scales represents rumination about individuals' life problems. In their recent study, the Cognitive Interference scale displayed a single-factor structure and exhibited adequate reliability and significant variability between persons and within persons over time.
Supporting concurrent validity of the items, Stawski (Stawski, Mogle, \& Sliwinski, 2011) found that Cognitive Interference was associated with both negative affect and daily stress.

\section{Data analysis}

Structural equation modelling (SEM) was performed using MPlus version 5.2 (Muthén \& Muthén, 2007). Because the observations between parent and offspring violated assumptions of independence and resulted in a nested structure (parent and offspring nested within family), there were important shared biological and environmental factors to be accounted for in data analysis. To correct the model for this nested structure, we included family membership as a clustering variable in the data and used the COMPLEX function in MPlus. This takes the shared family membership into account for all analyses. Descriptive statistics (Table 1) were calculated in SPSS (SPSS, 2009). Standard fit criteria were used to evaluate the overall model fit, with non-significant $\chi^{2}$ value, comparative fit index $(\mathrm{CFI})>0.95$, Tucker-Lewis index $(\mathrm{TLI})>0.90$, and root mean square error of approximation (RMSEA) $<0.06$ all indicating good fit (Hu \& Bentler, 1999). In large samples, such as the current study, the $\chi^{2}$ is often significant regardless of fit, due to sensitivity to large sample sizes; thus, one needs to rely on the other fit indicators (e.g. CFI, TLI and RMSEA) to examine model fit (Kline, 2005).

We developed two SEM models to better understand the role of rumination as a mediator. The first simple model excluded rumination to examine the direct relationships between parental factors (depressive symptoms and neuroticism) and offspring's depressive symptoms. In the second model, we examined the mediating role of rumination. To compare the two models, Akaike's information criterion (AIC) was used (Bozdo-gan, 1987; Hurvich \& Tsai, 1989). AIC provides an indicator of the model's fit, such that the betterfitting model has the smallest AIC. It should be noted that we controlled for important covariates 
of depression, specifically income, education, gender and minority status (Blazer, Sachs-Ericsson, \& Hybels, 2007).

\section{Results}

Model 1: direct effects of parental depression and neuroticism on offspring's depression

In the first model, we examined the association between parental depression and parental neuroticism on the offspring's depressive symptoms. Results are summarized in Table 2. In developing the SEM and examining the fit of the model, we found the item 'feeling hopeless' did not load well on the depression construct for parent's depression - and thus it was removed. However, it did load onto offspring's depression construct. Additionally, the item 'calm' did not load strongly onto the parental neuroticism construct and thus it was also removed to improve model fit.

Nonetheless, the model fit was marginal because CFI value was not greater than $0.95\left(\chi^{2}=100.832\right.$, d.f. $=39, p<0.01$, d.f. $=55, p<0.01, C F I=0.90$, $\mathrm{TLI}=0.90, \mathrm{RMSEA}=0.05, \mathrm{AIC}=15010.1) . \mathrm{Im}-$ portantly, we found both parental neuroticism $(\beta=0.168, \quad p=0.03)$ and parental depression $(\beta=0.156, p=0.043)$ predicted offspring's depression. As expected, the covariate offspring's income $(\beta=-0.234, p<0.01)$ predicted depression such that poorer individuals were more depressed. Surprisingly, gender did not predict offspring's depression. Education and minority status were also unrelated after controlling for income.

Table 2: Model 1: Direct relationship between parental depression, parental neuroticism and offspring's depression

\begin{tabular}{|c|c|c|c|c|}
\hline & Estimate & SE & Est./SE & $p$-value \\
\hline \multicolumn{5}{|l|}{ Latent constructs ${ }^{\mathrm{a}}$} \\
\hline \multicolumn{5}{|l|}{ Parent neuroticism by } \\
\hline Mood & 0.400 & 0.052 & 7.641 & $p<0.001$ \\
\hline Worry & 0.685 & 0.040 & 16.969 & $p<0.001$ \\
\hline Nervous & 0.846 & 0.041 & 20.511 & $p<0.001$ \\
\hline \multicolumn{5}{|l|}{ Parent depression by } \\
\hline Lonely & 0.700 & 0.035 & 20.188 & $p<0.001$ \\
\hline Blue & 0.803 & 0.031 & 25.815 & $p<0.001$ \\
\hline Lost interest & 0.667 & 0.038 & 17.471 & $p<0.001$ \\
\hline Worthless & 0.550 & 0.044 & 12.456 & $p<0.001$ \\
\hline \multicolumn{5}{|l|}{ Offspring's depression by } \\
\hline Lonely & 0.667 & 0.037 & 18.003 & $p<0.001$ \\
\hline Blue & 0.770 & 0.031 & 25.067 & $p<0.001$ \\
\hline Lost interest & 0.685 & 0.033 & 20.621 & $p<0.001$ \\
\hline Hopeless & 0.757 & 0.030 & 25.524 & $p<0.001$ \\
\hline Worthless & 0.778 & 0.028 & 27.568 & $p<0.001$ \\
\hline \multicolumn{5}{|c|}{ Latent constructs relationship structure ${ }^{\mathrm{b}}$} \\
\hline \multicolumn{5}{|l|}{ Offspring's depression on } \\
\hline Parental neuroticism & 0.168 & 0.078 & 2.158 & $p=0.031$ \\
\hline Parental depression & 0.156 & 0.077 & 2.022 & $p=0.043$ \\
\hline Child income & -0.234 & 0.055 & -4.233 & $p<0.001$ \\
\hline Child sex & 0.002 & 0.055 & 0.040 & $p=0.968$ \\
\hline Education & -0.037 & 0.038 & -0.980 & $p=0.327$ \\
\hline Minority & -0.108 & 0.079 & -1.368 & $p=0.171$ \\
\hline
\end{tabular}

a This is the development of the latent constructs by each item. These are the variables items that load onto each construct.

${ }^{\mathrm{b}}$ These represent how constructs are related to each other. 
To further explore the surprising lack of gender differences in depression, we examined the simple correlation between the offspring's summed depression score and offspring's gender in SPSS. The correlation was low but significant, $\quad(r=0.10$, $p=0.01)$. Thus, the variance from the other model indices may have obscured any gender differences in depression.

It should be noted that it is likely that parental neuroticism and depression share some variance. Indeed, the latent constructs parental depression and parental neuroticism were significantly correlated, $(r=0.519, p<0.001)$, lending support to their latent constructs.

\section{Model 2: rumination as a mediator}

In this second model, we included the construct offspring's rumination. The measurement model consisted of the four latent variables (parental depression, parental neuroticism, offspring's depression and offspring's rumination).

Structural model. The SEM model 2 provided a good fit to the data $\left(\chi^{2}=150.212\right.$, d.f. $=104$, $p<0.01, \mathrm{CFI}=0.96, \mathrm{TLI}=0.95, \mathrm{RMSEA}=0.04$, $\mathrm{AIC}=13716.4)$. AIC was used to compare Models 1 and 2. The better model has the smallest AIC. Thus, comparing Model $2(\mathrm{AIC}=13716.4)$ to that of Model 1 (AIC $=15010.1)$, we see Model 2 is a better representation of the data. The inclusion of the rumination in the model resulted in more precise relationships among the constructs and overall a more appropriate fit of the data

The model statistics are summarized in Table 3 and significant paths in the model are illustrated in Figure 1. Among the covariates, again the offspring's lower income $(\beta=-0.173, p<0.01)$ was related to offspring's depression. Again, gender was unrelated to depression. Education and minority status was unrelated. Critical to the hypotheses, offspring's rumination predicted offspring's depression $(\beta=0.55, p<0.01)$. Consistent with the literature, female gender predicted rumination $(\beta=0.126, p=0.029)$. However, unlike the first model in which depression and neuroticism predicted offspring's depression, in the model that included rumination, neither parental depression $(\beta=0.096, \mathrm{p}=0.173)$ nor neuroticism $(\beta=0.38$, $p=0.601)$ predicted offspring's depression. Also of interest, parental neuroticism predicted offspring's rumination $(\beta=0.181, p=0.026)$, but parental depression did not, suggesting that rumination may fully mediate the relationship between parental neuroticism and offspring's depression.

We examined whether the offspring's rumination mediated the relationship between parental neuroticism and the offspring's depression. We used the Model Indirect function in MPlus to generate indirect effect indices for the original source variables. In this model, offspring's rumination mediated the relationship between parental neuroticism and offspring's depression $(\beta=0.103$, $p=0.03)$.

Results suggest that the effects of parental neuroticism on offspring's depression may flow through rumination. The PRODCLIN programme (MacKinnon, Fritz, Williams, \& Lockwood, 2007; Tofighi \& MacKinnon, 2011) was used to provide a more stringent test of the mediational effect found with the indirect function in MPLUS. The PRODCLIN approach tests mediational effects without some of the problems inherent in other methods of testing for mediation (e.g. inflated rates of Type I error) (MacKinnon et al., 2002). PRODCLIN examines the product of the unstandardized path coefficients divided by the pooled standard error of the path coefficients $\left(\alpha \beta / \sigma_{\alpha \beta}\right)$, and a confidence interval is generated. If the values between the upper and lower confidence limits include zero, this finding suggests the absence of a statistically significant mediation effect. Thus the unstandardized path coefficients and standard errors of the path coefficients for effect of parental neuroticism on offspring's depression via rumination were entered into PRODCLIN programme (Tofighi \& MacKinnon, 2011) to yield lower and upper 95\% confidence limits of 0.012 and 0.192 . This result confirms 
Table 3: Model 2. The SEM Model that included Rumination as a Mediator.

\begin{tabular}{|c|c|c|c|c|}
\hline & Estimate & S.E. & Est./S.E. & P-Value \\
\hline \multicolumn{5}{|c|}{ LATENT CONSTRUCTS ${ }^{a}$} \\
\hline \multicolumn{5}{|c|}{ CHILD RUMINATION BY } \\
\hline Rumination Item 1 & 0.567 & 0.048 & 11.939 & $\mathrm{p}<0.001$ \\
\hline Rumination Item 2 & 0.727 & 0.049 & 14.862 & $\mathrm{p}<0.001$ \\
\hline Rumination Item 3 & 0.476 & 0.050 & 9.527 & $\mathrm{p}<0.001$ \\
\hline \multicolumn{5}{|c|}{ PARENTAL NEUROTICISM by } \\
\hline Mood & 0.357 & 0.052 & 6.919 & $\mathrm{p}<0.001$ \\
\hline Worry & 0.851 & 0.067 & 12.607 & $\mathrm{p}<0.001$ \\
\hline Nervous & 0.867 & 0.058 & 14.975 & $\mathrm{p}<0.001$ \\
\hline \multicolumn{5}{|c|}{ PARENTAL DEPRESSION by } \\
\hline Lonely & 0.656 & 0.047 & 13.921 & $\mathrm{p}<0.001$ \\
\hline Blue & 0.740 & 0.045 & 16.278 & $\mathrm{p}<0.001$ \\
\hline Lost interest & 0.531 & 0.042 & 12.769 & $\mathrm{p}<0.001$ \\
\hline Feel Worthless & 0.289 & 0.028 & 10.165 & $\mathrm{p}<0.001$ \\
\hline \multicolumn{5}{|l|}{ CHILD DEPRESSION by } \\
\hline Lonely & 0.712 & 0.053 & 13.475 & $\mathrm{p}<0.001$ \\
\hline Blue & 0.777 & 0.048 & 16.185 & $\mathrm{p}<0.001$ \\
\hline Lost Interest & 0.659 & 0.047 & 13.985 & $\mathrm{p}<0.001$ \\
\hline Hopeless & 0.652 & 0.042 & 15.543 & $\mathrm{p}<0.001$ \\
\hline Feel Worthless & 0.609 & 0.037 & 16.606 & $\mathrm{p}<0.001$ \\
\hline \multicolumn{5}{|c|}{ Latent Constructs relationship structure ${ }^{\mathrm{b}}$} \\
\hline \multicolumn{5}{|c|}{ CHILD RUMINATION on } \\
\hline Parental Neuroticism & 0.181 & 0.081 & 2.229 & $p=0.026$ \\
\hline Parental Depression & 0.062 & 0.081 & 0.767 & $\mathrm{p}=0.443$ \\
\hline \multirow[t]{2}{*}{ Child's Sex } & 0.126 & 0.058 & 2.181 & $\mathrm{p}=0.029$ \\
\hline & Estimate & S.E. & Est./S.E. & P-Value \\
\hline \multicolumn{5}{|l|}{ CHILD DEPRESSION on } \\
\hline Child Rumination & 0.550 & 0.054 & 10.212 & $\mathrm{p}<0.001$ \\
\hline Parental Depression & 0.096 & 0.070 & 1.363 & $p=0.173$ \\
\hline Parental Neuroticism & 0.038 & 0.072 & 0.523 & $p=0.601$ \\
\hline Child Sex & -0.107 & 0.062 & 1.719 & $p=0.086$ \\
\hline Child Income & -0.173 & 0.052 & -3.323 & $p<0.001$ \\
\hline Education & 0.001 & 0.035 & 0.038 & $\mathrm{p}=0.970$ \\
\hline Minority & -0.053 & 0.071 & -0.744 & $\mathrm{p}=0.457$ \\
\hline
\end{tabular}

${ }^{\mathrm{a}}$ This is the development of the latent constructs by each item. These are the variables items that load onto each construct. ${ }^{\mathrm{b}}$ These represent how constructs are related to each other.

In this model offspring's rumination mediated the relationship between parental neuroticism and depression $(\beta=.0 .103, p=0.03)$.

that rumination significantly mediated the association between parental neuroticism and the offspring's depression.

\section{Discussion}

Using structural equation modelling, we first examined the direct effects of parental depressive symptoms and parental neuroticism on the development of adult offspring's depressive symptoms. Consistent with the literature, we found that parental depression and neuroticism predicted offspring's depressive symptoms. In a second model, we examined the mediating role of offspring's rumination. Consistent with the literature (e.g. Hilt, McLaughlin, \& 


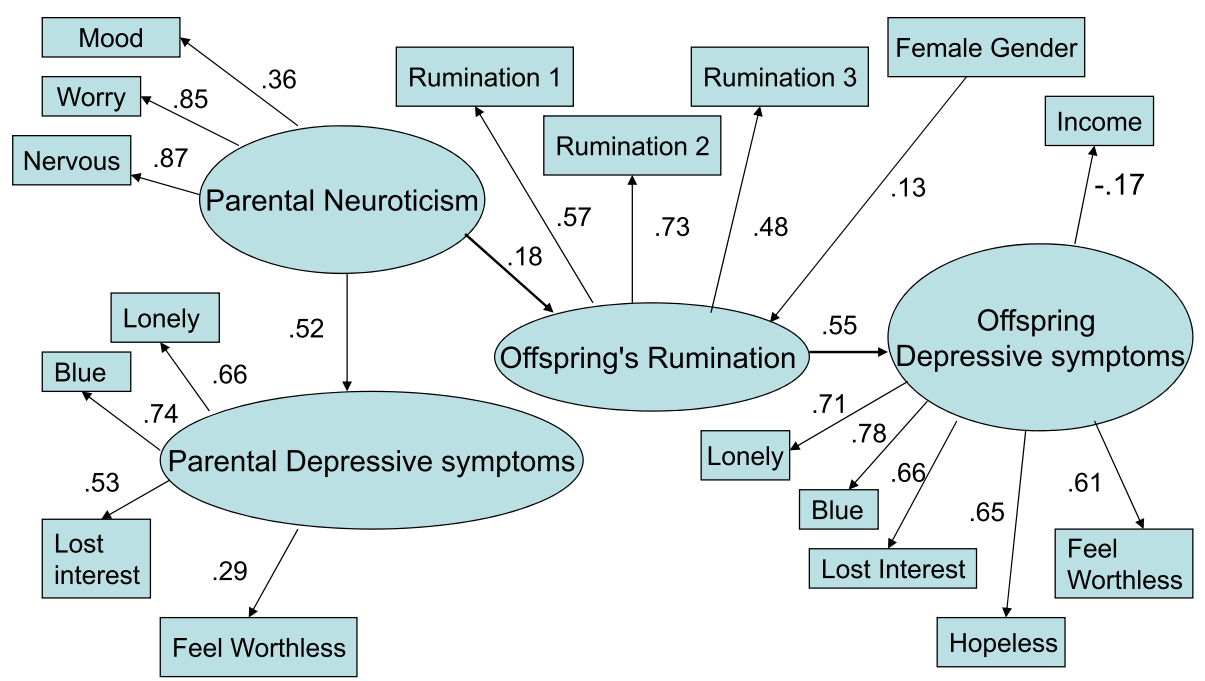

In this model offspring's rumination mediated the relationship between parental neuroticism and offspring's depression $(\beta=.0 .103, p=0.03)$.

Figure 1: The effects of parental neuroticism and depressive symptoms on offspring's depressive symptoms: the mediating role of rumination

Nolen-Hoeksema, 2011), we found that offspring's rumination predicted the latent construct offspring's depressive symptoms. Additionally, parental neuroticism, but not parental depression, predicted offspring's rumination. In turn, offspring's rumination fully mediated the relationship between parental neuroticism and offspring's depression. Others have found rumination to mediate the relationship between neuroticism and depression in clinical (Roelofs, Huibers, Peeters, Arntz, et al., 2008) and non-clinical samples (Roelofs, Huibers, Peeters, \& Arntz, 2008); however, this is the first study to our knowledge to provide evidence for this mediational relationship among parentoffspring dyads.

There are several potential explanations for these results. First, parental neuroticism may contribute to a family environment in which offspring are exposed to and then modelled ineffective coping strategies such as rumination (Hilt et al., 2011). This learned ruminative response style then places offspring at an increased risk for developing depression (e.g. Nolen-Hoeksema et al., 2008). Second, parental neuroticism may have a genetic influence on the development of offspring's rumination. In this regard, Roberts and colleagues (Roberts, Gilboa, \& Gotlib, 1998) suggest that rumination might reflect an important cognitive manifestation of neuroticism that increases vulnerability to episodes of persistent dysphoria. Parental neuroticism likely has both a genetic and an environmental influence on the development of offspring's rumination. Given the design of the current study, clarification of the mechanism (i.e. environmental or genetic influences) by which parental neuroticism leads to high levels of rumination in offspring cannot be inferred. Future research providing a better understanding of these underlying mechanisms may have implications for treatment and prevention of depression in high risk children.

\section{Treatment implications}

Considering the role that rumination plays in mediating the association between neuroticism and depressive symptoms-decreasing rumination 
in high risk individuals may be important in reducing onset of depressive disorders (Haeffel, 2010). Therapy that decreases rumination and increases productive problem-solving may reduce onset and relapse rates of depression (Wilkinson, Croudace, \& Goodyer, 2013). Indeed studies of depressed individuals have found that a treatment that focuses on reducing rumination (e.g. rumination-focused CBT) is associated with better outcomes (Lam, Smith, Checkley, Rijsdijk, \& Sham, 2003; Watkins et al., 2007).

There are several limitations to consider in drawing firm conclusions from the study's results. In the current study, we did not include a measure of parent's rumination. Thus, we were unable to assess whether parent's rumination predicted the offspring's rumination, which would provide a more direct test of the modelling hypothesis. Indeed, disturbances in maternal cognitions (e.g. rumination), have been shown to play a significant role in mother-infant interaction (Stein et al., 2012). In a recent study, rumination in mothers was associated with depression in adolescent girls in Isfahan high schools (Jafari, Yousefi, \& Manshaee, 2014). However, whereas children of depressed mothers brood more than children of non-depressed mothers, in one study, this difference did not appear to be due to modelling of the mother's rumination (Gibb, 2012).

In the second SEM model, we failed to find the expected relationship between parental depression and offspring's rumination or an association between parental depression and offspring's depression. In the first model, there was a direct relationship between parental depression (as well as neuroticism) and offspring's depression. Limitations in the measure of depression for both parents and offspring may have influenced results. The measure of depression was limited to five items assessing participants' mood for the week prior to the survey. There was no measure of current or past history of clinical depression. Thus, this measure may have mostly identified the most severe cases of depression, as they would be most likely to be depressed on any given week of the year (including the week of the survey). This limitation likely affected the power to detect a relationship between parental depressive symptoms and offspring's depression as well as the possible mediating effects of the offspring's rumination. We should note, however, that the moderate correlation between the latent constructs of parental neuroticism and parental depressive symptoms does suggest validity of the depression measure. Second, the significant association between parental depression and offspring's depression in the first model also suggests validity of the depression measure. Nonetheless, limitations in our measure of depression may have obscured the findings in the current study.

Further, temporal precedence and the direction of the relationship between parental neuroticism and the offspring's level of rumination and depressive symptoms cannot be established due to the cross-sectional design of the study. Future research should use a longitudinal design to test this mediation model so that causal inferences about the temporal relationship among the variables can be made.

The current study had several strengths. First, the study included a large sample of parent/offspring dyads from relatively diverse economic and ethnic backgrounds, and there was an even distribution of parent (mother or father) and child (son or daughter) relationships. Second, addressing limitations of previous research, parents and offspring were interviewed separately, and we did not rely on the offspring's report of parental psychiatric symptoms. Third, SEM was used to analyse the data. SEM allows for a complex understanding of the relationship among constructs, and it accounts for measurement error, thus producing more reliable information about the relationships among variables (Muthén \& Muthén, 2007). PRODCLIN was also used to provide a stringent test of the proposed mediation model.

\section{Conclusion}

The current study provided evidence that parental neuroticism predicted adult offspring's rumination; 
moreover, the offspring's rumination predicted depressive symptoms; and rumination fully mediated the relationship between parental neuroticism and the offspring's depressive symptoms. However, given the limitations in the measures (e.g. depression, neuroticism and rumination) and the cross-sectional nature of the design-this suggest the importance of further replication. A replication of the study with a longitudinal design and a measure of parent's rumination would be quite informative.

We have speculated as to whether parental neuroticism may contribute a genetic predisposition in the offspring for a ruminative coping style or if it may have promoted a family environment in which maladaptive cognitive processes such as rumination are learned. Targeting rumination in treatment of high risk individuals may decrease the risk of depression.

\section{References}

Abramson, L. Y., Seligman, M. E., \& Teasdale, J. D. (1978). Learned helplessness in humans: Critique and reformulation. Journal of Abnormal Psychology, 87(1), 49-74.

APA. (2006). APA Dictionary of Psychology, Washington, DC: American Psychological Association.

Belle Doucet, D. J. (2003). Poverty, inequality, and discrimination as sources of depression among U.S. women. Psychology of Women Quarterly, 27(2), 101-113. doi: 10.1111/14716402.00090

Blane, D., Smith, G. D., \& Bartley, M. (1993). Social selection: What does it contribute to social class differences in health? Sociology of Health 6 Illness, 15(1), 1-15. doi: 10.1111/ j.1467-9566.1993.tb00328.x

Blazer, D., Sachs-Ericsson, N., \& Hybels, C. (2007). Perception of unmet basic needs as a predictor of depressive symptoms among community-dwelling older adults. Journal of Gerontology: Medical Sciences, 62, 191-195.

Bozdo-gan, H. (1987). Model selection and Akaike's information criterion: The general theory and its analytical extensions. Psychometrika, 52(3), 345-370.

Clark, L. A., Watson, D., \& Mineka, S. (1994). Temperament, personality, and the mood and anxiety disorders. Journal of Abnormal Psychology, 103(1), 103-116.

Cohen-Woods, S., Craig, I. W., \& McGuffin, P. (2013). The current state of play on the molecular genetics of depression. Psychological Medicine, 43(04), 673-687. doi:10.1017/ S0033291712001286

Derogatis, L. R. (2000). Brief symptom inventory. In H. P. A. Rush, M. First, D. Blacker, J. Emndicott, S. Keith, et al.
(Ed.), The handbook of psychiatric measures. Washington, D. C.: The American Psychiatric Association.

Derogatis, L. R., \& Melisarator, N. (1983). The brief symptom inventory: An introductory report. Psychological Medicine, 3, 595-605.

Derogatis, L. R. Savitz, K. L. (2000). The SCL-90-R and the brief symptom inventory (BSI) in primary care. In M. E. Maruish (Ed.), Handbook of psychological assessment in primary care settings (Vol. 236, pp. 297-334). Mahwah, NJ: Lawrence Erlbaum Associates.

Eysenck, H. J., \& Eysenck, S. B. G. (1975). Manual of the Eysenck personality questionnaire. London, England: Hodder \& Stoughton.

Fingerman, K., Miller, L., Birditt, K., \& Zarit, S. (2009). Giving to the good and the needy: Parental support of grown children. Journal of Marriage and Family, 71(5), 1220-1233.

Gibb, B. E. (2012). Brooding rumination and risk for depressive disorders in children of depressed mothers. Journal of Abnormal Child Psychology, 40(2), 317-326. doi: 10.1007/ s10802-011-9554-y

Goldberg, L. R. (1992). The development of markers for the big-five factor structure. Psychological Assessment, 4, 26-42.

Goodman, S. H., \& Gotlib, I. H. (1999). Risk for psychopathology in the children of depressed mothers: A developmental model for understanding mechanisms of transmission. Psychological Review, 106(3), 458-490. doi: 10.1037/0033-295x.106.3.458

Groves, R., \& Mathiowetz, N. (1984). Computer assisted telephone interviewing: Effects on interviewers and respondents. Public Opinion Quarterly, 48(1B), 356-369. doi: $10.1093 / \mathrm{poq} / 48.1$ B.356

Haeffel, G. J. (2010). When self-help is no help: Traditional cognitive skills training does not prevent depressive symptoms in people who ruminate. Behaviour Research and Therapy, 48, 152-157.

Hankin, B. (2008). Rumination and depression in adolescence: Investigating symptom specificity in a multiwave prospective study. Journal of Clinical Child and Adolescent Psychology, 37(4), 701-713.

Hervas, G., \& Vazquez, C. (2011). What else do you feel when you feel sad? Emotional overproduction, neuroticism and rumination. Emotion, 11(4), 881-895.

Hilt, L. M., Armstrong, J. M., \& Essex, M. J. (2011). Early family context and development of adolescent ruminative style: Moderation by temperament. Cognition $\mathcal{E}$ Emotion, 1-11. doi: 10.1080/02699931.2011.621932

Hilt, L. M., Armstrong, J. M., \& Essex, M. J. (2012). Early family context and development of adolescent ruminative style: Moderation by temperament. Cogn Emot, 26(5), 916-926.

Hirschfeld, R. M. A., Klerman, G. L., Clayton, P. J., Keller, M. B., McDonald-Scott, P., \& Larkin, B. (1983). Assessing personality: Effects of the depressive state on trait measurement. Am J Psychiatry, 140, 695-699. 
Hu, L.-T., \& Bentler, P. M. (1999). Cutoff criteria for fit indexes in covariance structure analysis: Conventional criteria versus new alternatives. Structural Equation Modeling: A Multidisciplinary Journal, 6(1), 1-55.

Hurvich, C. M., \& Tsai, C. (1989). Regression and time series model selection in small samples. Biometrika, 76, 297-307.

Jafari, F., Yousefi, Z., \& Manshaee, G. (2014). Mothers characters and adolescence depression. Open Journal of Depression, 3 45-51. doi: 10.4236/ojd.2014.32010

Kendler, K. S., Heath, A., Martin, N. G., \& Eaves, L. J. (1986). Symptoms of Anxiety and Depression in a Volunteer Twin Population: The Etiologic Role of Genetic and Environmental Factors. Arch Gen Psychiatry, 43(3), 213-221. doi: 10.1001/archpsyc.1986.01800030023002

Kendler, K. S., Neale, M. C., Kessler, R. C., Heath, A. C., \& Eaves, L. J. (1993). A longitudinal twin study of personality and major depression in women. Arch Gen Psychiatry, 50(11), 853-862. doi: 10.1001/ archpsyc. 1993.01820230023002

Kendler, K. S., Gatz, M., Gardner, C. O., \& Pedersen, N. L. (2006). Personality and Major Depression: A Swedish Longitudinal, Population-Based Twin Study. Archives of General Psychiatry, 63(10), 1113-1120.

Kline, R. B. (2005). Details of path analysis Structural Equation Modeling (second Ed., pp. 133-135). New York: Guildford Press.

Krueger, R. F. (1999). The structure of common mental disorders. Arch Gen Psychiatry, 56(10), 921-926.

Lachman, M. E., \& Weaver, S. L. (1997). The midlife development inventory (MIDI) personality scales: Scale construction and scoring (Technical Report). Brandeis University, Waltham, MA.

Lam, D., Smith, N., Checkley, S., Rijsdijk, F., \& Sham, P. (2003). Effect of neuroticism, response style and information processing on depression severity in a clinically depressed sample. Psychol Med, 33(3), 469-479.

Lo, C. S. L., Ho, S. M. Y., \& Hollon, S. D. (2008). The effects of rumination and negative cognitive styles on depression: A mediation analysis. Behaviour research and therapy, 46(4), 487-495. doi: 10.1016/j.brat.2008.01.013

Mackinnon, D. P., Fritz, M. S., Williams, J., \& Lockwood, C. M. (2007). Distribution of the product confidence limits for the indirect effect: Program PRODCLIN. Behavior Research Methods, 39, 384-389.

Mackinnon, D. P., Lockwood, C. M., Hoffman, J. M., West, S. G., \& Sheets, V. (2002). A comparison of methods to test mediation and other intervening variable effects. Psychological Methods, 7(1), 83-104.

McCrae, R. R., \& Costa Jr, P. T. (1997). Personality trait structure as a human universal. American Psychologist, 52(5), 509-516. doi: 10.1037/0003-066x.52.5.509

Mezulis, A., \& Rudolph, M. (2012). Pathways linking temperament and depressive symptoms: A short-term prospective diary study among adolescents. Cogn Emot, 26(5), 950-960.

Mezulis, A. H., Priess, H. A., \& Hyde, J. S. (2011). Rumination mediates the relationship between infant temperament and adolescent depressive symptoms. Depression Research and Treatment, 2011, 9. doi: 10.1155/2011/487873

Moberly, N. J., \& Watkins, E. R. (2008). Ruminative selffocus and negative affect: An experience sampling study. Journal of Abnormal Psychology, 117(2), 314-323. doi: 10.1037/0021-843x.117.2.314

Monroe, S. M., \& Reid, M. W. (2008). Gene-environment interactions in depression research. Psychological Science, 19(10), 947-956. doi: 10.1111/j.1467-9280.2008.02181.x

Moore, M. N., Salk, R. H., Van Hulle, C. A., Abramson, L. Y., Hyde, J. S., Lemery-Chalfant, K., \& Goldsmith, H. H. (2013). Genetic and environmental influences on rumination, distraction, and depressed mood in adolescence. Clinical Psychological Science, 1(3), 316-322. doi: 10.1177/2167702612472884

Mroczek, D. K., Kolarz, C. M. (1998). The effect of age on positive and negative affect: A developmental perspective on happiness. Journal of Personality and Social Psychology, 75, 1333-1349.

Muris, P., Roelofs, J., Rassin, E., Franken, I., \& Mayer, B. (2005). Mediating effects of rumination and worry on the links between neuroticism, anxiety and depression. Personality and Individual Differences, 39(6), 1105-1111. doi: $10.1016 /$ j.paid.2005.04.005

Muthén, L. K., \& Muthén, B. O. (2007). Mplus User's Guide Fifth Edition (1998-2007).

Natsuaki, M., Shaw, D., Neiderhiser, J., Ganiban, J., Harold, G., Reiss, D., \& Leve, L. (2014). Raised by depressed parents: Is it an environmental risk? Clinical Child and Family Psychology Review, 10 May 2014, 1-11. doi: 10.1007/ s10567-014-0169-z

Nolan, S., Roberts, J., \& Gotlib, I. (1998). Neuroticism and ruminative response style as predictors of change in depressive symptomatology. Cognitive Therapy and Research, 22(5), 445-455. doi: 10.1023/a:1018769531641

Nolen-Hoeksema, S. (1991). Responses to depression and their effects on the duration of depressive episodes. Journal of Abnormal Psychology, 100(4), 555-561.

Nolen-Hoeksema, S. (2000). The role of rumination in depressive disorders and mixed anxiety/depressive symptoms. J Abnorm Psychol, 109(3), 504-511.

Nolen-Hoeksema, S., Wisco, B. E., \& Lyubomirsky, S. (2008). Rethinking rumination. Perspectives on Psychological Science, 3(5), 400-424. doi: 10.1111/j.17456924.2008.00088.x

Papageorgiou, C., \& Wells, A. (2008). Nature, functions, and beliefs about depressive rumination. Depressive Rumination (pp. 1-20). The Atrium, Southern Gate, Chichester, West Sussex PO19 8SQ, England: John Wiley \& Sons Ltd. 
Pennsylvania State Data Center (2001). Research brief: New standards for defining metropolitan statistical areas announced. Harrisburg: Institute of State and Regional Affairs.

Plant, E. A., \& Sachs-Ericsson, N. (2004). Racial and ethnic differences in depression: The roles of social support and meeting basic needs. Journal of Consulting and Clinical Psychology, 72(1), 41-52.

Plomin, R., De Fries, J., \& McClearn, G., et al. (2001). Behavioural Genetics (4th Edition). NYC, NY: New York Freeman.

Prenda, K. M., \& Lachman, M. E. (2001). Planning for the future: A life management strategy for increasing control and life satisfaction in adulthood. Psychology and Aging, 16, 206-216.

Rice, F., Harold, G. T., \& Thapar, A. (2002). Assessing the effects of age, sex and shared environment on the genetic aetiology of depression in childhood and adolescence. Journal of Child Psychology and Psychiatry, 43(8), 1039.

Rice, F., Harold, G., Shelton, K., \& Thapar, A. (2006). Family conflict interacts with genetic liability in predicting childhood and adolescent depression. J Am Acad Child Adolesc Psychiatry, 45(7), 841-848.

Roberts, J. E., Gilboa, E., \& Gotlib, I. H. (1998). Ruminative response style and vulnerability to episodes of dysphoria: Gender, neuroticism, and episode duration. Cognitive Therapy and Research, 22(4), 401-423.

Roelofs, J., Huibers, M., Peeters, F., \& Arntz, A. (2008). Effects of neuroticism on depression and anxiety: Rumination as a possible mediator. Personality and Individual Differences, 44(3), 576-586.

Roelofs, J., Huibers, M., Peeters, F., Arntz, A., \& van Os, J. (2008). Rumination and worrying as possible mediators in the relation between neuroticism and symptoms of depression and anxiety in clinically depressed individuals. Behaviour Research and Therapy, 46(12), 1283-1289.

Spasojević, J., \& Alloy, L. B. (2001). Rumination as a common mechanism relating depressive risk factors to depression. Emotion, 1(1), 25-37. doi: 10.1037/15283542.1.1.25

SPSS (2009). Statistical Package for Social Science. Chicago: SPSS INC.

Staudinger, U. M., Fleeson, W., \& Baltes, P. B. (1999). Predictors of subjective physical health and global well-being:
Similarities between the United States and Germany. Journal of Personality and Social Psychology, 76, 305-319.

Stawski, R. S., Mogle, J., \& Sliwinski, M. J. (2011). Intraindividual coupling of daily stressors and cognitive interference in old age. The Journals of Gerontology, Series B: Psychological Sciences and Social Sciences, 66B(S1), 121-129. doi: 10.1093/geronb/gbr012

Stein, A., Craske, M. G., Lehtonen, A., Harvey, A., SavageMcGlynn, E., Davies, B., \& Counsell, N. (2012). Maternal cognitions and mother-infant interaction in postnatal depression and generalized anxiety disorder. J Abnorm Psychol, 121(4), 795-809.

Sullivan, P. F., Neale, M. C., \& Kendler, K. S. (2000). Genetic Epidemiology of Major Depression: Review and Meta-Analysis. Am J Psychiatry, 157(10), 1552-1562. doi: 10.1176/appi.ajp.157.10.1552

Tofighi, D., \& MacKinnon, D. P. (2011). RMediation: An R package for mediation analysis confidence intervals. Behavior Research Methods, 43, 692-700.

Turiano, N. A., Mroczek, D. K., Moynihan, J., \& Chapman, B. P. (2013). Big 5 personality traits and interleukin-6: Evidence for "healthy Neuroticism" in a US population sample. Brain, Behavior, and Immunity, 28(0), 83-89. doi: 10.1016/j.bbi.2012.10.020

Verstraeten, K., Vasey, M. W., Raes, F., \& Bijttebier, P. (2009). Temperament and risk for depressive symptoms in adolescence: Mediation by rumination and moderation by effortful control. Journal of Abnormal Child Psychology, 37(3), 349-361. doi: 10.1007/s10802-008-9293-x

Watkins, E., Scott, J., Wingrove, J., Rimes, K., Bathurst, N., Steiner, H., \& Malliaris, Y. (2007). Rumination-focused cognitive behaviour therapy for residual depression: A case series. Behaviour Research and Therapy, 45(9), 2144-2154. doi: 10.1016/j.brat.2006.09.018

Wilkinson, P., Croudace, T., \& Goodyer, I. (2013). Rumination, anxiety, depressive symptoms and subsequent depression in adolescents at risk for psychopathology: A longitudinal cohort study. BMC Psychiatry, 13(1), 250.

Address correspondence: Natalie Sachs-Ericsson, Ph.D.; Department of Psychology, Florida State University, 1107 W. Call Street, Tallahassee, FL 32306, USA. Email: sachs@psy.fsu.edu 